\section{Case Reports in Oncology}

\title{
Ductal Adenocarcinoma of the Prostate: A Case Report
}

\author{
Yutaro Hayashi $^{\mathrm{a}}$ Takashi Kawahara $^{\mathrm{a}, \mathrm{b}}$ Hiromichi Iwashita $^{\mathrm{c}}$ \\ Kota Shimokihara ${ }^{a}$ Sohgo Tsutsumi ${ }^{a}$ Daiji Takamoto ${ }^{a}$ \\ Taku Mochizuki $^{\mathrm{a}} \quad$ Yusuke Hattori $^{\mathrm{a}}$ Jun-ichi Teranishi ${ }^{\mathrm{a}}$ \\ Yasuhide Miyoshi $^{\mathrm{a}}$ Yasushi Yumura $^{\mathrm{a}}$ Masahiro Yao $^{\mathrm{b}}$ \\ Yoshiaki Inayama ${ }^{c}$ Hiroji Uemura ${ }^{a}$ \\ a Departments of Urology and Renal Transplantation, Yokohama City University Medical

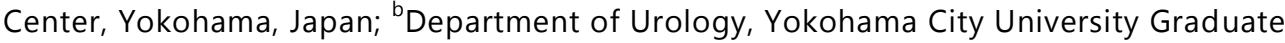 \\ School of Medicine, Yokohama, Japan; 'Department of Diagnostic Pathology, Yokohama \\ City University Medical Center, Yokohama, Japan
}

\section{Keywords}

Prostate cancer · Ductal carcinoma

\begin{abstract}
Ductal adenocarcinoma is an unusual variant of adenocarcinoma of the prostate. A 73-yearold male was referred to our hospital for the further examination of an elevated prostatespecific antigen level of $23.4 \mathrm{ng} / \mathrm{mL}$. Radical prostatectomy (RP) was performed based on the diagnosis obtained by a prostate needle biopsy. The RP specimen revealed ductal adenocarcinoma of the prostate with positive capsular penetration. We herein report a rare case of ductal adenocarcinoma of the prostate.

\section{Introduction}

Ductal adenocarcinoma of the prostate was first reported by Melicow and Pachter [1] in 1967 as an endometrial carcinoma prostatic utricle. Since then, ductal adenocarcinoma of 
the prostate has been found to account for $0.2-7.5 \%$ of all prostate carcinomas [2]. We herein report a rare case of ductal adenocarcinoma of the prostate.

\section{Case Presentation}

A 73-year-old man was referred to our hospital due to an elevated prostate-specific antigen (PSA) level of $23.4 \mathrm{ng} / \mathrm{mL}$. He had no remarkable medical history. The hematological and biochemical data showed no abnormal findings aside from the elevated PSA levels. In February 2016, a prostate needle biopsy detected Gleason score $4+4$ adenocarcinoma in his left prostate. Computed tomography (CT) and bone scintigraphy showed no distant metastasis. Magnetic resonance imaging (MRI) showed a higher density on his left peripheral zone (Fig. 1a, b). In May 2016, radical prostatectomy with lymph node resection was performed.

\section{Operative Procedure and Pathological Findings}

Histologically, there were many large, clear-edged cells and cancer cells with low differentiation forming a circular shape. High cylindrical differentiated epithelium collated papillary and cribriform. Acinar adenocarcinoma was partially mixed in these areas (Fig. 2). No lymph node metastasis was observed. Based on these findings, ductal adenocarcinoma and Gleason score $4+4=8$ acinar adenocarcinoma with positive surgical margin were diagnosed.

\section{Postoperative Course}

No adverse perioperative events were observed. The patient has not experienced recurrence or biochemical recurrence in the 10 months since radical prostatectomy.

\section{Discussion}

Ductal adenocarcinoma of the prostate was first reported as endometrial carcinoma of the prostatic utricle in 1967 [1]. Recent studies have suggested that ductal adenocarcinoma of the prostate developed from the ductal epithelium, based on findings from immunohistochemical and electron microscope analyses. Histologically, ductal adenocarcinoma of the prostate is characterized by high cylindrical epithelium collate papillary or etat cribriform. The histological differences between ductal adenocarcinoma and acinar adenocarcinoma are thought to be clear. In this case, although the prostate needle biopsy showed acinar adenocarcinoma, the surgical specimens showed ductal adenocarcinoma.

Ductal adenocarcinoma of the prostate is divided into 2 types. The first is a mixed type with acinar adenocarcinoma and accounts for $<75 \%$ of ductal prostate specimens. The other is a pure type, which accounts for $\geq 75 \%$ of ductal adenocarcinoma. Mixed-type ductal prostate adenocarcinomas account for $5.0-6.6 \%$ of all prostate cancer cases, and pure-type ductal prostate adenocarcinomas account for $0.4-0.8 \%$ of all prostate cancer cases [3]. Because ductal carcinomas account for $90 \%$ of all prostatic carcinoma cases, our case was assumed to be pure type.

Because of its extension toward the urethra, the tumor was not palpable on a digital rectal examination and showed a low PSA level [4]. Ductal adenocarcinoma of the prostate usually extends toward the urethra and shows macrohematuria and urinary symptoms at an early stage. 
The prognosis of ductal adenocarcinoma of the prostate is still controversial. Morgan et al. [4] reported that ductal adenocarcinoma of the prostate showed a significantly poorer prognosis than acinar prostate adenocarcinoma in nonmetastatic cases. However, in metastatic cases, there were no prognostic differences between these 2 groups [4]. Other reports have found no marked differences in the 5 -year survival rate between ductal adenocarcinoma and Gleason score 8-10 acinar adenocarcinoma [5].

Reported therapies of ductal adenocarcinoma of the prostate are also the same as for acinar adenocarcinoma, including radical prostatectomy, androgen deprivation therapy, and radiation therapy or a combination of these therapies. Perrapato et al. [6] reported that pure ductal adenocarcinoma tended to extend into the submucosal urethra; as such, pure ductal adenocarcinoma carries a higher risk of a positive surgical margin in the urethra. This case also showed positive surgical margins. Although we are not performing adjuvant therapy in this patient at present, careful observation including CT, MRI, or positron emission tomography-CT should be performed, as PSA does not always accurately represent cancer progression [7].

We herein reported a rare case of ductal adenocarcinoma of the prostate.

\section{Statement of Ethics}

We obtained written informed consent for this study.

\section{Disclosure Statement}

The authors declare that they have no competing interests.

\section{References}

1 Melicow MM, Pachter MR: Endometrial carcinoma of proxtatic utricle (uterus masculinus). Cancer 1967;20:1715-1722.

2 Izumi K, Kanno H, Umemoto S, Hasumi H, Osada Y, Ota J, Tsuchiya F, Ogino I, Harada M: A case of ductal carcinoma of the prostate after transurethral resection of prostate (in Japanese). Hinyokika Kiyo 2007;53:315-318.

3 Colpaert C, Gentens P, Van Marck E: Ductal ("endometrioid") adenocarcinoma of the prostate. Acta Urol Belg 1998;66:29-32.

-4 Morgan TM, Welty CJ, Vakar-Lopez F, Lin DW, Wright JL: Ductal adenocarcinoma of the prostate: increased mortality risk and decreased serum prostate specific antigen. J Urol 2010;184:2303-2307.

-5 Packiam VT, Patel SG, Pariser JJ, Richards KA, Weiner AB, Paner GP, VanderWeele DJ, Zagaja GP, Eggener SE: Contemporary population-based comparison of localized ductal adenocarcinoma and highrisk acinar adenocarcinoma of the prostate. Urology 2015;86:777-782.

-6 Perrapato SD, Shah PC, Huben RP, Gaeta JF: Locally recurrent endometrioid adenocarcinoma of the prostate after radical prostatectomy. J Urol 1991;145:373-375.

-7 Leibovici D, Spiess PE, Agarwal PK, Tu SM, Pettaway CA, Hitzhusen K, Millikan RE, Pisters LL: Prostate cancer progression in the presence of undetectable or low serum prostate-specific antigen level. Cancer 2007;109:198-204. 


\section{Case Reports in Oncology}

\begin{tabular}{l|l}
\hline Case Rep Oncol 2016;9:802-805 \\
\hline DOI: 10.1159/000453448 & $\begin{array}{l}\text { ○ 2016 The Author(s). Published by S. Karger AG, Basel } \\
\text { www.karger.com/cro }\end{array}$ \\
\hline Hayashi et al.: Ductal Adenocarcinoma of the Prostate: A Case Report
\end{tabular}
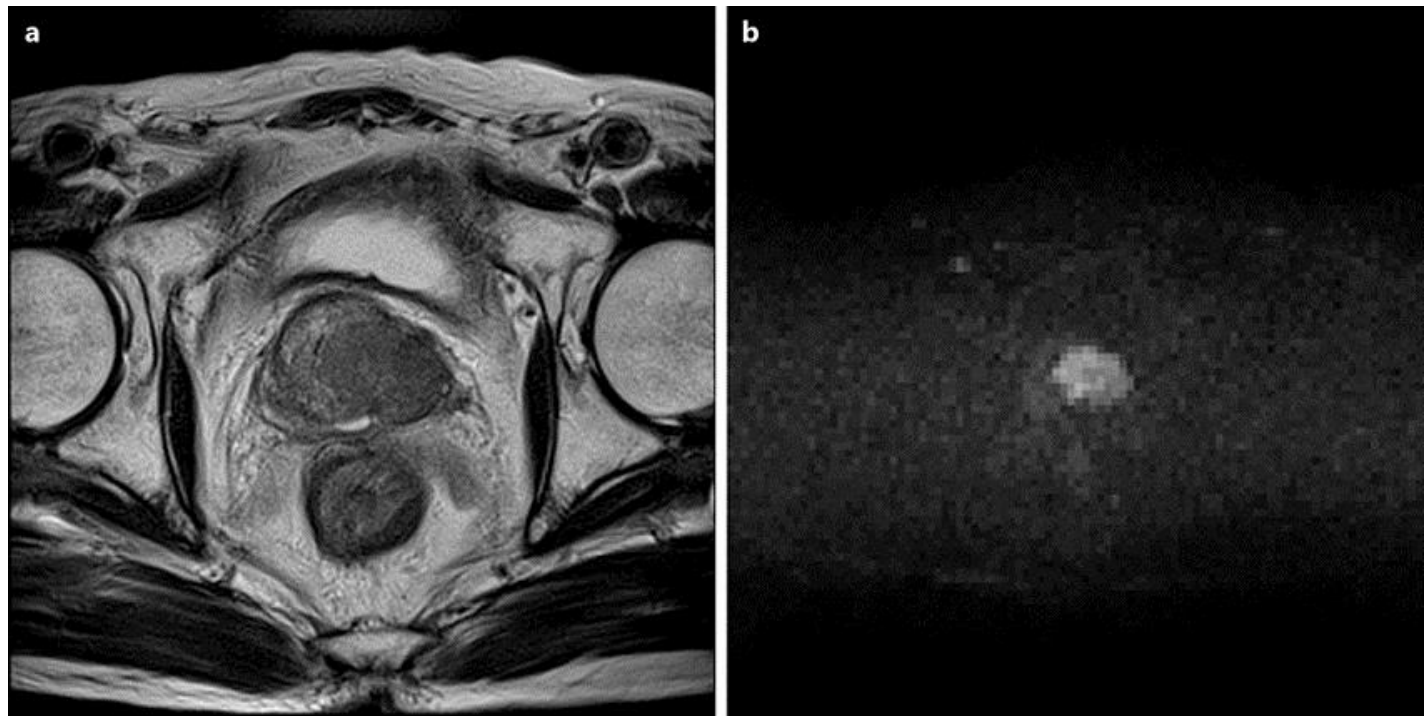

Fig. 1. MRI findings: T1-weighted image (a) and T2-weighted image (b).

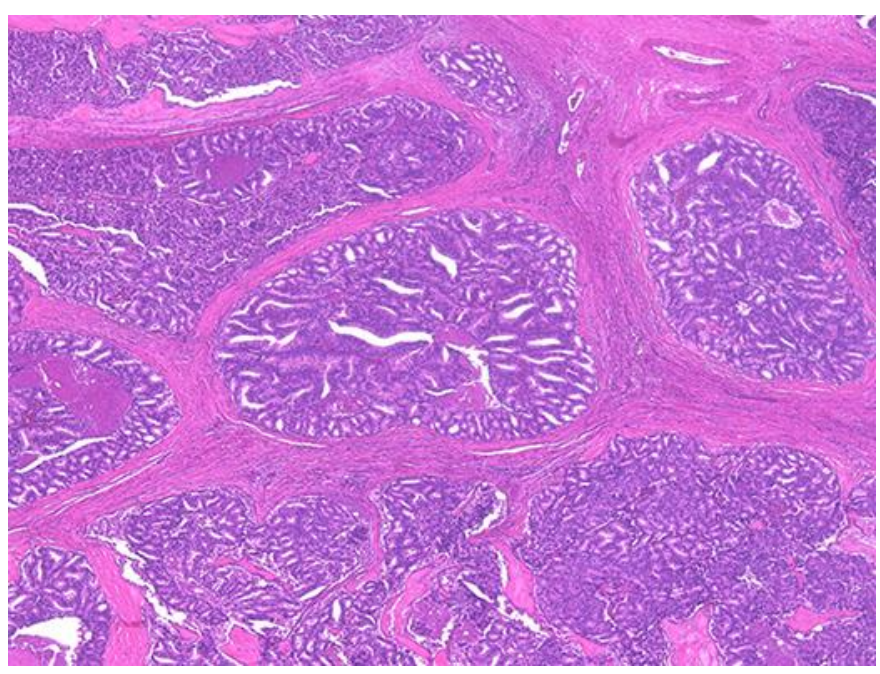

Fig. 2. HE stain. 